\title{
Planning with Goal Programming: A Case Study for Multiple-Use of Forested Land
}

\author{
Paul A. Arp and Daniel R. Lavigne ${ }^{1}$
}

\begin{abstract}
A case study is provided to develop and demonstrate a general goal programming procedure for hierarchical multiple land-use planning of forested lands with variable planning horizons. Four land-use policies containing timber harvesting, dispersed recreation, developed recreation, hunting and wildlife management are considered for a parcel of land incorporating $11,070 \mathrm{ha}$. The goals for each type of land-use are analyzed in terms of land-use capability coefficients, various priority settings, and planning horizons spanning from 2 to 36 years. It is shown that multiple-use conflicts can be resolved by either changing the priorities associated with conflicting uses, and (or) by extending planning horizons from shortto medium-term or long-term.
\end{abstract}

\section{Key Words:}

Land-use planning, multiple-use, goal programming, timber, developed and dispersed recreation, hunting, wildlife.

\section{Résumé}

Une étude de cas est présentée en vue d'élaborer et d'éprouver une méthode générale de programmation par objectif dans une planification d'utilisations multiples et hiérarchisées du territoire forestier et cela avec des horizons variables. Quatre énoncés de politique d'utilisation du territoire touchant 11,070 hectares ont été considérés, soit la production de bois, la récréation extensive, la récréation intensive et la production de faune. Les objectifs de chacun des types d'utilisation ont été analysés en terme de coefficients de capacité d'utilisation, de priorités établies et d'horizons de planification allant de $\mathbf{2}$ à 36 ans. Il est montré que les conflits inhérents aux utilisations multiples peuvent être résolus ou en changeant les priorités associées aux utilisations en conflit ou en faisant passer les horizons de planification de court à moyen ou long terme.

Mots vedettes: Plan d'aménagement, utilisations multiples, programmation par objectif, production de bois, récréation extensive et intensive, chasse, faune sauvage.

\section{Introduction}

Multiple land-use decision making involves consideration of geographic, socio-economic and temporal constraints. Goal programming, a quantitative decision making tool based on linear programming, may guide the land-use planner to:

(i) list and evaluate all land-use constraints and demands in a systematic manner,

${ }^{1}$ P.A. Arp, Assist. Prof.; D.R. Lavigne, Teaching Assist.; Dept. of Forest Resources, University of New Brunswick, Fredericton, NB, Canada. Enquiries should be sent to P.A. Arp. (ii) separate crucial information from extraneous, irrelevant and (or) repetitive data,

(iii) develop conceptual insight of the land-use decision making environment by quantifying perceived goals, options, and priorities,

(iv) evaluate such goals, options and priorities in terms of land capability by way of computer calculations in the hope of gaining an improved land-use perspective, or - in the ideal case - formulating a number of generally acceptable if not optimal land-use plans (Bottoms 1976).

Goal programming for forest management has found many advocates in recent years (Field 1973; Rustagi 1973; Bell 1976; Bottoms 1976; Dane et al. 1977). The technique, in general, may serve as a rational means for bridging the often highly emotional gap between industrial, environmental, and public concerns regarding forested land. Yet goal programming is not a panacea against poor planning (Bell 1976). In fact, goal programming may not necessarily yield optimal solutions unless several precautions are taken (Dyer et al. 1979; Field et al. 1980; Hrubes and Rensi 1981). Non-optimal solutions are particularly prevalent when the general decisionmaking environment is complex and an attempt is made to place all relevant information into one all-encompassing program.

The purpose of this paper is to encourage further use of goal programming in forestry by highlighting a relatively simple yet realistic quantitative procedure obtained by splitting the overall problem into at least two recognizable hierarchical levels (Duerr et al. 1979), by varying the planning horizon, and by formulating a number of competitive land-use policy groups. The procedure is outlined step-by-step and is applied to a case study involving 11070 ha of forested land for which information regarding physiography, timber inventory, basic land-use policies and goals is available (CFB Gagetown Landuse Plan, 1980)

Linear programming techniques other than goal programming have also been found suitable for land-use planning although their proper formulation is perhaps less well structured than the organized procedure of goal programming. Examples for such techniques with illustrative case studies for land-use planning are given by Ware and Clutter (1971), Burckhardt et al. (1978), Steuer and Schuler (1978), and Omi et al. (1981). Particularly noteworthy is the land-use study of Nautiyal et al. (1975) employing mixed-integer programming for optimal land allocation near Sault Ste. Marie, Ontario.

\section{The Goal Programming Procedure}

Several steps are required to represent a multiple land-use problem by quantitative relationships. These steps are:

(i) Delineate the area of interest and divide it into workable management units (compartments), where such units may be defined by physiographic boundaries or actual land-use pattern already in place.

(ii) For each compartment, carefully examine all possible and realistic uses, and determine several alternative land-use policies subject to existing socio-economic needs and demands. 
(iii) Identify the goal for each need and demand considered in step (ii) and examine the relationship between all the resulting goals as function of planning horizon (number of target years). Obviously, the relationship between the goals may be quite different for short ( $<5$-year), medium (5-to 15-year), or long-term ( $>15$-year) plans.

(iv) Identify the constraints associated with the land-use of the area, e.g. acreage per compartment.

(v) Determine the land capability coefficients " $a_{i j}$ " for each land-use "j" contributing to goal " $\mathrm{g}_{\mathrm{i}}$ " (see below).

(vi) Establish the priorities associated with each goal.

(vii) Obtain the optimal land-use allocation for each goal and priority setting by linear programming.

Algebraically, this procedure is formulated as follows (Dyer et al. 1979; Lee, 1972):

$$
\begin{array}{ll}
\text { Minimize } & \mathbf{Z}=\mathbf{P}^{-} \cdot \mathbf{d}^{-}+\mathbf{P}^{+} \cdot \mathbf{d}^{+} \\
\text {subject to } & \mathbf{A} \cdot \mathbf{x}=\mathbf{g}+\mathbf{d}^{+}-\mathbf{d}^{-}, \\
& \mathbf{B} \cdot \mathbf{x} \leq \mathbf{C}, \\
& \mathbf{x}, \mathbf{d}^{+}, \mathbf{d}^{-} \geq 0,
\end{array}
$$

where $\mathbf{d}^{+}=\left(d_{1}^{+}, d_{2}^{+}, \ldots\right)$ and $\mathbf{d}^{-}=\left(d_{1}^{-}, d_{2}^{-}, \ldots\right)$ are vectors listing the positive and negative deviations from the goals $\mathbf{g}\left(\mathrm{g}_{1}, \mathrm{~g}_{2} \ldots\right)$ for each perceived need or demand, respectively; vectors $\mathbf{P}^{+}=\left(\mathrm{P}_{1}^{+}, \mathrm{P}_{2}^{+}, \ldots\right)$ and $\mathbf{P}^{-}=\left(\mathrm{P}^{-}{ }_{1}, \mathrm{P}_{2}, \ldots\right)$ list the priority factors associated with $\mathbf{d}^{+}$and $\mathbf{d}^{-}$, respectively. Matrix A represents a 2-dimensional array of the land capability coefficients $a_{i j}$ per acre for each compartment (column j) and goal (row i); $\mathbf{x}=\left(\mathrm{x}_{1}, \mathrm{x}_{2}, \ldots\right)$ lists the as yet unknown number of acres to be assigned to each particular use on a compartment-by-compartment basis.

Physical land-use constraints (such as acreage per compartment) are represented by vector $\mathbf{C}=\left(\mathbf{C}_{1}, \mathbf{C}_{2}, \ldots\right)$; $\mathbf{B}$ is a 2-dimensional listing of the corresponding constraint coefficients.

The overall objective is to allocate land acreage (i.e. deter- mine $\mathbf{x}$ ) such that $Z$, the sum of the priority weighted deviations from the goals, is minimized. It is assumed that $\mathbf{A}$ and B adequately represent the geographic constraints and capabilities of the land, and that vectors $\mathbf{g}$ and $\mathbf{P}$ reflect the relevant socio-economic situation as accurately as possible.

\section{The Case Study}

\section{The Area}

The location and features of the area of study are shown in Figure 1. This area is divided into ten distinct compartments separated from one another by current land-use boundaries and existing road networks. Qualitative and quantitative landuse capability ratings of each compartment for dispersed and developed recreation, hunting and wildlife are described below. The land is part of the Canadian Forces Base at Gagetown, NB, and represents an area for which restricted use by the public is considered.

\section{Defining Policy}

Policy assignments per compartment are made according to the following land uses:
1. dispersed recreation,
2. developed recreation,
3. hunting,
4. timber harvesting, and
5. wildlife.

For each compartment, two groups (Groups I and II) of four complementary or alternative land-use policies (A, B, C and D) are suggested as shown in Table 1. For example, policy C in Group I includes activities 3 to 5 but excludes 1 and 2 . In the second group, hunting is excluded from all recreational
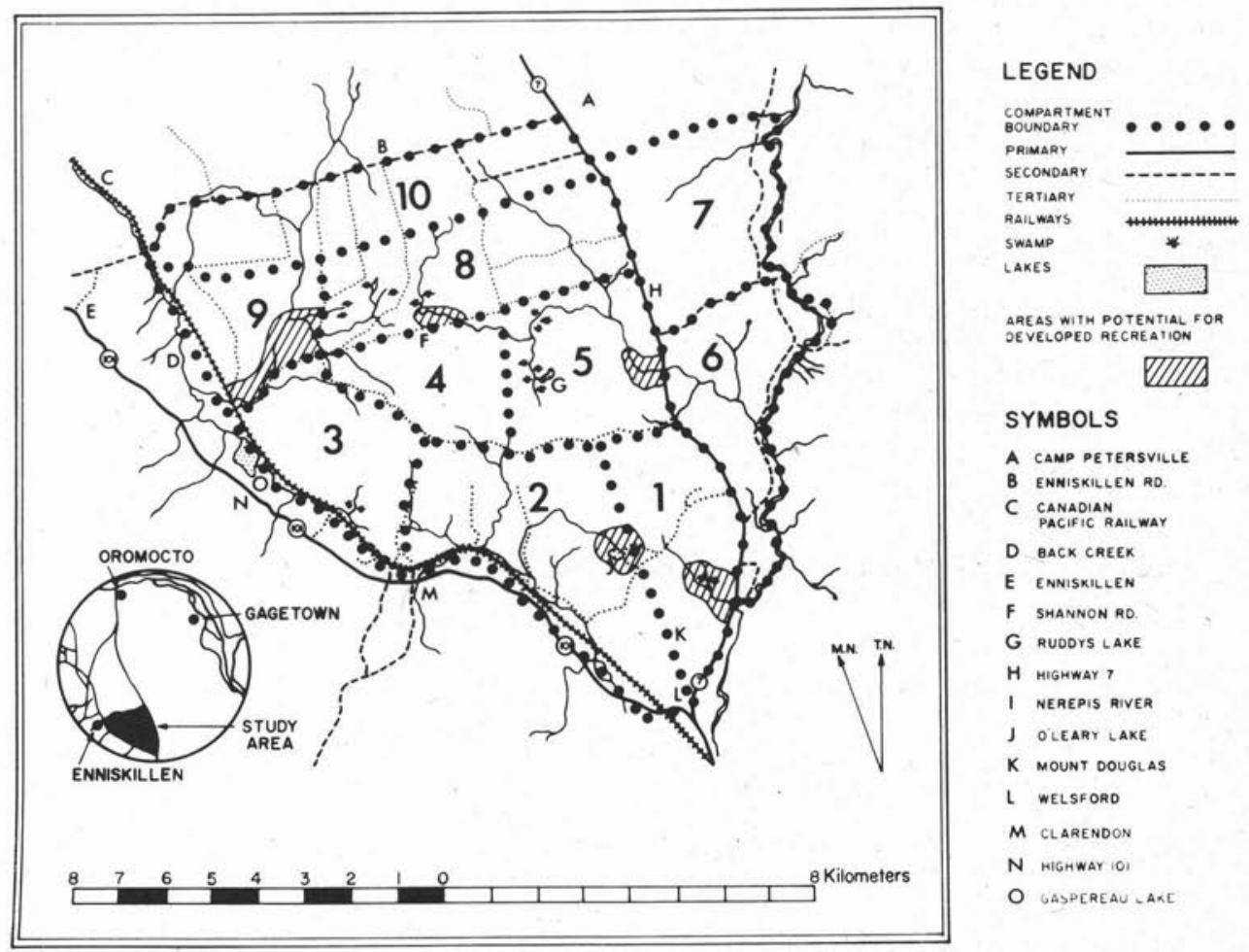

\section{SYMBOLS}

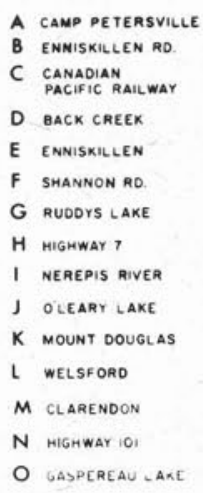

Figure 1. Map of study area near Gagetown, New Brunswick. Shown are several important land-use features, including locations and boundaries for each compartment i.e. landuse planning unit. 
Taile 1. Land-use policies A, B, C and D with (Group II) and without (Group I) hunting restrictions.

$\begin{array}{cccccccc} & \text { Group I } & & & \text { Group } & 11 & & \\ \text { A } & B & C & D & \text { A } & B & C & D\end{array}$

Land Use
1. Dispersed Recreation
2. Developed Recreation
3. Hunting
4. Tiniber Harvesting
5. Wildife

activities in the hope of avoiding mutual interferences and reducing the risk of lamentable accidents. Policy D represents the best combination of uses for the non-merchantable timberlands all of which, at present, are unattractive for recreational use. Policies $\mathrm{B}$ and $\mathrm{C}$ are meant to imply that harvesting operations enhance wildlife habitats as much as possible, and improve the general accessibility to these areas.

\section{The goals and planning horizons}

The goals for the various land-uses, i.e. timber, dispersed and developed recreation, hunting and wild life management are developed for the 2-, 12- and 36-year planning horizons. The annual non-timber goals remain fixed and are not allowed to change from year to year. The timber goal, however, increases in proportion to the planning horizon and represents the cumulative allowable cut for the area. A 12-year planning horizon, for example, earmarks $120000 \mathrm{~m}^{3}$ of standing merchantable timber to policy $\mathrm{B}$ and $\mathrm{C}$, allowing policy $\mathrm{A}$ to be effective over the remaining timber lands. The specific goal assignments of the other uses are given below in connection with the land capability coefficients. These goals reflect our personal estimates and do not relate to any stated or unstated policy of the land-owner.

\section{The constraints}

The constraints considered are the acreage constraints for each compartment in terms of merchantable and unmerchantable forest land as shown in Table 2. Other constraints, such as access to each compartment and wildlife carrying capacities, are not included in this study, but can be incorporated if desirable.

\section{The land capability coefficients}

(a) Timber

The total merchantable timber volume for each cover-type was used to calculate the average volume of merchantable wood per hectare within each compartment (Table 2). These values, in turn, represent the timber coefficients associated with the harvesting goal identified with the annual allowable cut of $10000 \mathrm{~m}^{3}$.

\section{(b) Dispersed recreation}

The potential for dispersed recreation can be tapped by developing a controlled network of trails and facilities for activities such as hiking, snow-shoeing, cross-country skiing and interpretive walks. The suitability and capability of such prospects are dependent upon a number of physical, topographic and biological features such as broad relief, variety of land pattern, rockiness, soil depth, wetness, and nature of soil material (Hill et al. 1971). Other features relate to topographic and vegetative variety, location of lakes, streams and rivers, scenic and visual qualities, and the presence (or lack) of manmade structures within the same area (Burnett and Conklin 1979). Suitable combinations of these features are identified

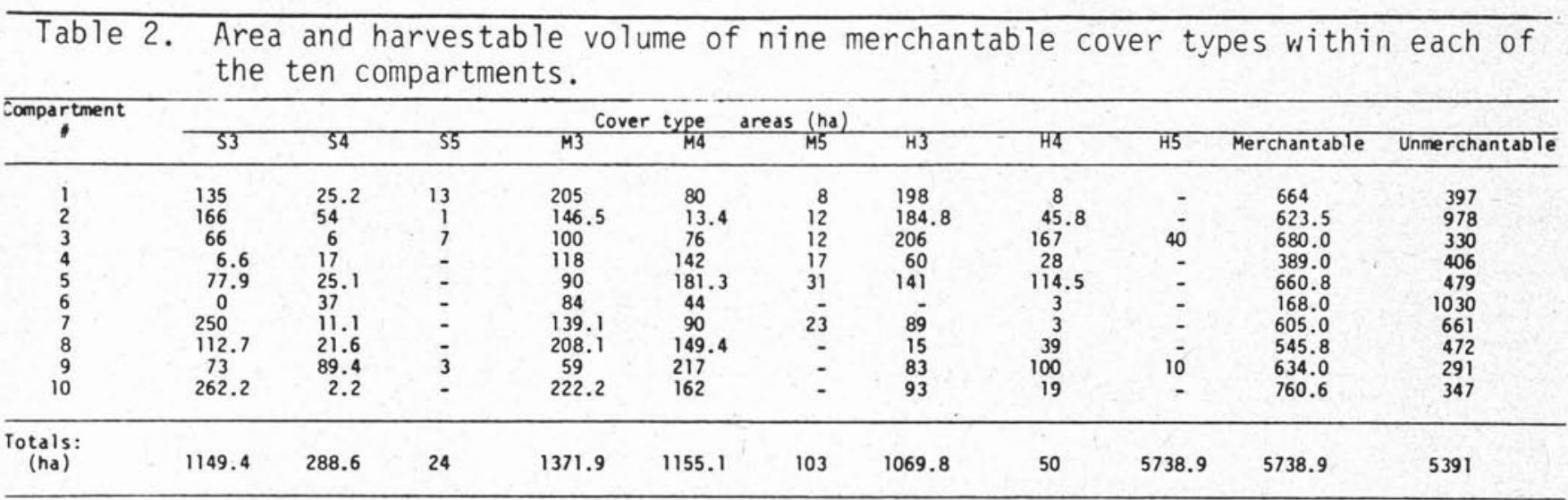

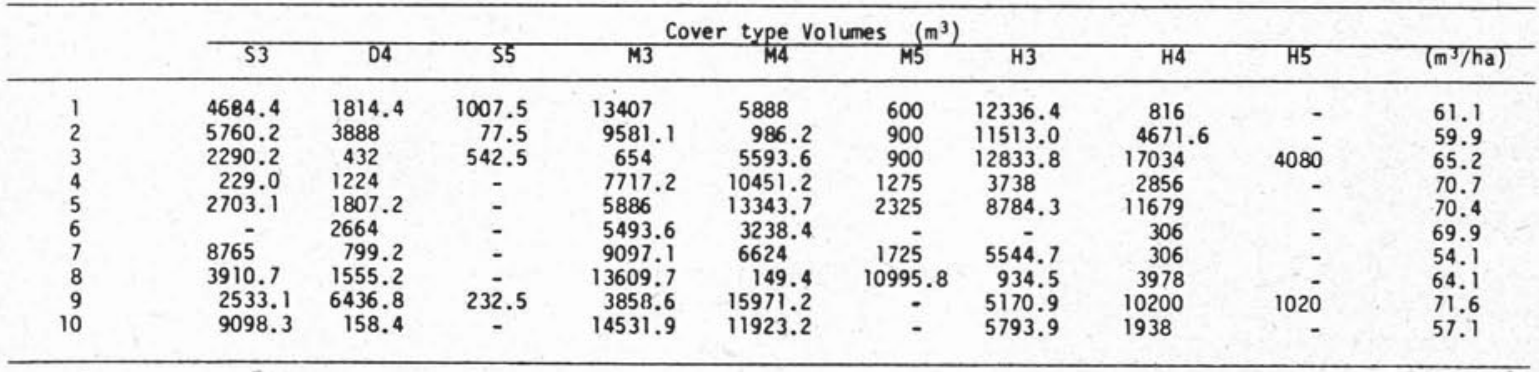

$\therefore$ Cover type:

S : 70-100\% sof twood

M: $31-698$ sof twood

$\mathrm{H}: 0-30 \%$ softwood
Cutting class:

3: Immature stands

4 : Maturing or mature

5 : Mature or overmature stands
Age (years) Height (m)

$31-50 \quad 10-17$

$51-70$

over 17

71 plus over 17 
Table 3. Land capability coefficients for dispersed and developed recreation, and wildlife use.

Dispersed recreation:

\begin{tabular}{|c|c|c|c|c|c|c|c|c|c|c|c|c|}
\hline \multirow{2}{*}{ Parameter } & \multirow{2}{*}{ Rating } & \multirow{2}{*}{$\begin{array}{l}\text { Recreational } \\
\text { Value } \\
\text { (v.d./acre/yr) }\end{array}$} & \multicolumn{10}{|c|}{ Compartment 1} \\
\hline & & & 1 & 2 & 3 & 4 & 5 & 6 & 7 & 8 & 9 & 10 \\
\hline Orainage & $\begin{array}{l}G \\
F \\
P\end{array}$ & $\begin{array}{l}.75 \\
.50 \\
.25\end{array}$ & $x$ & $x$ & $x$ & $x$ & $x$ & $x$ & $x$ & $x$ & $x$ & $x$ \\
\hline Soll Depth & $\begin{array}{l}G \\
F \\
P\end{array}$ & $\begin{array}{l}.75 \\
.50 \\
.25\end{array}$ & $x$ & $x$ & $x$ & $x$ & $x$ & $x$ & $x$ & $x$ & $x$ & $x$ \\
\hline $\begin{array}{l}\text { Topographic } \\
\text { Variety }\end{array}$ & $\begin{array}{l}G \\
F \\
P\end{array}$ & $\begin{array}{l}.75 \\
.50 \\
.25\end{array}$ & $x$ & $x$ & $x$ & $x$ & $\mathrm{x}$ & $x$ & $x$ & $x$ & $x$ & $x$ \\
\hline $\begin{array}{l}\text { Vegetative } \\
\text { Variety }\end{array}$ & $\begin{array}{l}G \\
F \\
p\end{array}$ & $\begin{array}{l}.75 \\
.50 \\
.25\end{array}$ & $x$ & $x$ & $x$ & $x$ & $x$ & $x$ & $x$ & $x$ & $x$ & $x$ \\
\hline $\begin{array}{l}\text { Abundance } \\
\text { of water }\end{array}$ & $\begin{array}{l}G \\
F \\
0\end{array}$ & $\begin{array}{l}.75 \\
.50 \\
.25\end{array}$ & $\mathrm{x}$ & $x$ & $x$ & $\mathrm{x}$ & $x$ & ${ }^{x}$ & $x$ & $x$ & $x$ & $x$ \\
\hline $\begin{array}{l}\text { Other Site } \\
\text { Factors }\end{array}$ & $\begin{array}{l}G \\
F \\
P\end{array}$ & $\begin{array}{l}.75 \\
.50 \\
.25\end{array}$ & $x$ & $x$ & $x$ & $x$ & $x$ & $x$ & $x$ & $x$ & $x$ & $x$ \\
\hline $\begin{array}{r}\text { Total } \\
\text { Land-use A } \\
\text { Land-use B }\end{array}$ & $\begin{array}{l}\text { d. /acre/yr } \\
\text { d./ha//yr } \\
\text { d./ha/yr) }\end{array}$ & & $\begin{array}{l}2.50 \\
6.25 \\
3.90\end{array}$ & $\begin{array}{l}3.00 \\
7.50 \\
4.69\end{array}$ & $\begin{array}{l}3.75 \\
9.38 \\
5.90\end{array}$ & $\begin{array}{l}3.00 \\
7.50 \\
4.69\end{array}$ & $\begin{array}{l}3.75 \\
9.38 \\
5.90\end{array}$ & $\begin{array}{l}2.50 \\
6.25 \\
3.90\end{array}$ & $\begin{array}{l}2.50 \\
6.25 \\
3.90\end{array}$ & $\begin{array}{l}2.25 \\
5.62 \\
3.51\end{array}$ & $\begin{array}{l}2.35 \\
8.12 \\
5.10\end{array}$ & $\begin{array}{l}2.25 \\
5.62 \\
3.51\end{array}$ \\
\hline
\end{tabular}

Wildlife:

\begin{tabular}{|c|c|c|c|c|c|c|c|c|c|c|c|c|}
\hline \multirow{2}{*}{ Paraneter } & \multirow{2}{*}{ Rating } & \multirow{2}{*}{$\begin{array}{c}\text { Value } \\
\text { (no. deer } \\
\text { /ha) }\end{array}$} & \multicolumn{10}{|c|}{ Compartment } \\
\hline & & & 1 & 2 & 3 & 4 & 5 & 6 & 7 & 8 & 9 & 10 \\
\hline $\begin{array}{l}\text { Pattern of } \\
\text { Forest and } \\
\text { Clearcuts }\end{array}$ & $\begin{array}{l}G \\
F \\
P\end{array}$ & $\begin{array}{l}.0050 \\
.0033 \\
.0017\end{array}$ & $x$ & $\mathbf{x}$ & $x$ & $x$ & $x$ & $x$ & $x$ & $x$ & $x$ & $x$ \\
\hline $\begin{array}{l}\text { Avallability } \\
\text { of Water }\end{array}$ & $\begin{array}{l}G \\
F \\
P\end{array}$ & $\begin{array}{l}.0050 \\
.0033 \\
.0017\end{array}$ & $x$ & $x$ & $x$ & $x$ & $x$ & $x$ & $x$ & $x$ & $x$ & $x$ \\
\hline $\begin{array}{l}\text { Abundance } \\
\text { of Browse }\end{array}$ & $\begin{array}{l}G \\
F \\
P\end{array}$ & $\begin{array}{l}.0050 \\
.0033 \\
.0017\end{array}$ & $\times$ & $x$ & $x$ & $x$ & $x$ & $x$ & $x$ & $x$ & $x$ & $x$ \\
\hline $\begin{array}{l}\text { Deer/ha: for } P \\
\text { Deer/ha: for } P \\
\text { Deer/ha: for } P\end{array}$ & $\begin{array}{l}\text { Olicy } A \\
\text { olicy } B \text { and } C \\
\text { olicy } D\end{array}$ & & $\begin{array}{l}.0116 \\
.0139 \\
.010\end{array}$ & $\begin{array}{l}.0116 \\
.0139 \\
.010\end{array}$ & $\begin{array}{l}.0133 \\
.0160 \\
.010\end{array}$ & $\begin{array}{l}.0084 \\
.010 \\
.010\end{array}$ & $\begin{array}{l}.0133 \\
.0160 \\
.010\end{array}$ & $\begin{array}{l}.010 \\
.012 \\
.010\end{array}$ & $\begin{array}{l}.0117 \\
.014 \\
.010\end{array}$ & $\begin{array}{l}.0099 \\
.0118 \\
.010\end{array}$ & $\begin{array}{l}.0083 \\
.0099 \\
.010\end{array}$ & $\begin{array}{l}.0117 \\
.014 \\
.010\end{array}$ \\
\hline
\end{tabular}

\section{Developed recreation:}

\begin{tabular}{cccc}
\hline Compartment & $\begin{array}{c}\text { Unadjusted } \\
\text { rating } \\
\text { (v.d./ha/yr) }\end{array}$ & $\begin{array}{c}\text { Areas within each } \\
\text { compartment (ha) }\end{array}$ & $\begin{array}{c}\text { Adjusted } \\
\text { rating } \\
\text { (v.d./ha/yr) }\end{array}$ \\
\hline 1 & 5.0 & 15 & .113 \\
2 & 7.5 & 25 & .300 \\
5 & 5.0 & 25 & .089 \\
8 & 5.0 & 10 & .046 \\
9 & 5.0 & 40 & .315 \\
\hline
\end{tabular}

and quantified. Numerical estimates for the dispersed recreation capability coefficients of each compartment are given in Table 3 in terms of number of visitor-days/acre/year. This number according to Dane et al. (1977) should not exceed 4.0 visitor-days/acre/year. This value was used as a quantitative guide in ranking the poor, fair and good ratings of each parameter in Table 3 from 0 to 4 v.d./acre/year. The demand goal for dispersed recreation for the entire area is set at 1000 dispersed visitor days/year. (c) Developed recreation

Developed recreation, depending on the planning horizon, may refer to picnicking and overnight camping (short-term), fixed trail facilities (medium-term), and beach development, golf-courses and centralized tourist attractions (long-term). Features capable of supporting developed recreation per compartment may include: attractive streams, lakes, or rivers, dust-free (or fairly dust-free) roads permitting easy access, and mature stands in combination with (or without) well- 
groomed open land. Any such features are high-lighted in Figure 1. To obtain quantitative estimates for the land capability coefficients for developed recreation, one may use a scale ranging from 1.6 to $3.00 \mathrm{dev}$. visitor days/acre/year (Dane et al., 1977) to describe the recreational capability of open land versus that of forested land. Developed recreation capability ratings of $5.0 \mathrm{v}$.d./ha/year represent areas containing rivers and streams, and ratings of $7.5 \mathrm{v} . \mathrm{d} . / \mathrm{ha} / \mathrm{year}$ represent areas containing lakes. A combination for these ratings is obtained for each compartment by calculating the percentage contribution of each such recreational possibility in terms of its potential area allocation (Table 3).

The demand (goal) for developed recreation is set a 320 dev. v.d/year for the four summer months.

\section{(d) Hunting}

Dane et al. (1977) assign capability ratings of 0.02 hunterdays/acre/year to non-harvested timber land, and 0.15 hunterdays/acre/year to harvested timberlands. Hence the land-use capability coefficients for hunting are given by 0.05 and 0.375 hunter-days/acre/year (CFB Gagetown Land-Use Plan 1980). Other species such as moose (attracting 225 big-game hunter-days in 1978) and small game species such as rabbit and grouse have contributed less significantly to hunting in the area. An acceptable hunting goal is to maintain hunting at current demand.

\section{(e) Wildlife}

Deer populations according to provincial statistics (CFB Gagetown Land-use plan 1980) have increased steadily in recent years leading to a total harvest of 33 animals in the area. The wildlife demand or goal in terms of the sustainable number of deer required to meet current annual harvest depends on:

(i) winter and summer mortality (considered to be $25 \%$ ),

(ii) the ratio of male and female deer surviving the winter (assumed to be 45/55), and

(iii) the birth rate, i.e. number of fawns/does (assumed to be 1.5 fawns/doe).

Following these assumptions, one can show that the fall supply of deer (i.e. the wildlife goal) prior to the hunting season should be 125 animals.

Three parameters are important to deer production: pattern and size of clearcutting, and the availability of water. These factors were examined and combined to obtain numerical ratings for the land capability coefficients for wildlife (Table 3). Normally, land capability coefficients for deer fluctuate around 0.10 deer/ha. Productivity, however, may be increased by perhaps as much as $20 \%$ (personal estimate) by controlled timber harvesting of forested lands.

Controlled timber harvesting, therefore, should be considered essential to implement land-use policies B and C. The land-use capability coefficients for hunting in Table 3 are therefore adjusted upwards by $20 \%$ in comparison to those of policy A. The population density on lands subject to policy $D$ is set at 0.010 deer/ha.

\section{Priority settings}

Four priority settings (cases) are considered (Table 4). In Case 1, all priority factors are set equal to 1 to demonstrate that multiple-use conflicts do arise. Top priority is given to timber harvesting in Case 2. Developed recreation and timber harvesting share top priority in Case 3 . In Case 4, developed recreation receives top priority, while timber harvesting takes second place. The preemptive priority factors for Case 2, 3, and 4 are calculated using the algorithm suggested by Field
(1973). The priority factor in Case 4 is adjusted for each planning horizon to maintain developed recreation as top priority. The timber goal for the 36-year planning horizons involves all present-day merchantable timber (Table 2) to be cut. Overcutting, in general, is deemed twice less desirable than undercutting, i.e. $\mathrm{P}_{4}^{-}=2 \mathrm{P}_{4}^{+}$. Table 4. Priority factors for four alter-
native priority settings (cases)
of land-use.

\begin{tabular}{|c|c|c|c|c|c|c|c|c|c|}
\hline \multirow[t]{2}{*}{ Case } & \multicolumn{2}{|c|}{$\begin{array}{l}\text { Dispersed } \\
\text { Recreation }\end{array}$} & \multicolumn{2}{|c|}{$\begin{array}{l}\text { Developed } \\
\text { Recreation }\end{array}$} & \multicolumn{2}{|c|}{ Hunting } & $\begin{array}{l}\text { Timber } \\
\text { Harvesting }\end{array}$ & \multicolumn{2}{|c|}{ Wildlife } \\
\hline & $p_{i}^{*}$ & $p_{1}^{+}$ & $P_{2}^{-}$ & $p_{2}^{+}$ & $P_{3}^{-}$ & $P_{3}^{+}$ & $P_{4}^{-} P_{4}^{+}$ & $P_{5}^{*}$ & $P_{5}^{+}$ \\
\hline 1. & 1 & 1 & 1 & 1 & 1 & 1 & 11 & 1 & 1 \\
\hline 2 & $\underline{0}^{*}$ & 1 & $\underline{b}^{*}$ & 1 & 1 & 1 & $\underline{a}^{*} \underline{2 a^{*}}$ & 1 & 1 \\
\hline 3 & $\underline{b}^{*}$ & 1 & $\stackrel{\mathrm{a}^{* *}}{=}$ & 1 & 1 & 1 & $\stackrel{\mathrm{d}^{*}}{\underline{2 \mathrm{a}^{* *}}}=$ & 1 & 1 \\
\hline 4: 2 years & 1 & 1 & $c+1^{* * *}$ & 1 & 1 & 1 & $\underline{\mathrm{e}}^{*} \underline{\underline{2 e}}$ & 1 & 1 \\
\hline $4: 12$ years & 1 & 1 & $\underline{6 c+1}{ }^{* *}$ & 1 & 1 & 1 & $\underline{e}^{*} \underline{2} \underline{e}^{*}$ & 1 & 1 \\
\hline $4: 36$ years & 1 & 1 & $\underline{d}^{* *}$ & 1 & 1 & 1 & $\underline{e} \underline{2 e}$ & 1 & 1 \\
\hline
\end{tabular}

$d=958001 ; b=958 ; c=20,020,000 ; d=364,935,571 ; e=1001$.

* top priority, * second priority, all others third priority.

\section{Computations}

The various land capability coefficients and ground levels for land-use policy group I are listed in Table 5 in the initial SIMPLEX tableau format (Hillier and Lieberman 1974). Variables $x_{1}$ to $x_{40}$ are the as yet unknown average assignments per land-use and compartment. Variables $x_{41}$ to $x_{50}$ are the as yet unknown deviations from each goal for each priority setting and planning horizon. Two additional variables for each compartment are used to incorporate the merchantable and unmerchantable land acerage constraints into the linear program, e.g.

and

$$
x_{1}+x_{2}+x_{3}+x_{51}=664 \text { ha (merchantable land) }
$$

$$
x_{4}+x_{52}=397 \text { ha (unmerchantable land) }
$$

for compartment 1. These constraints are not shown in Table 5 , but the complete initial SIMPLEX tableau is used to obtain the optimal solutions for $\mathbf{x}, \mathbf{d}^{+}$and $\mathbf{d}^{-}$for each priority setting (Case 1, 2, 3 and 4), planning horizon (2-, 12- and 36 -years) and policy group (I and II). The results provided in Table 6 and 7 were obtained with a TRS- 80 microcomputer using the SIMPLEX program developed by Manning (1971). His original FORTRAN program was changed into BASIC and modified to allow for:

(i) extensive computer-user interactions in conversational mode,

(ii) solution of linear programming problems containing " $\leq$ ", " $\geq$ " and " $=$ " constraints, and " =" (approximately equal to), " $\geq$ " (approximately greater), and " ¿" (approximately less than) goals,

(iii) flexibility in modifying the objective function and the numerical values for each goal, constraint and matrix coefficient.

The modified program, therefore, may be of general interest, has educational value, and is available on request. 
Table 5. Goal programming: matrix formulation (initial simplex tableau).

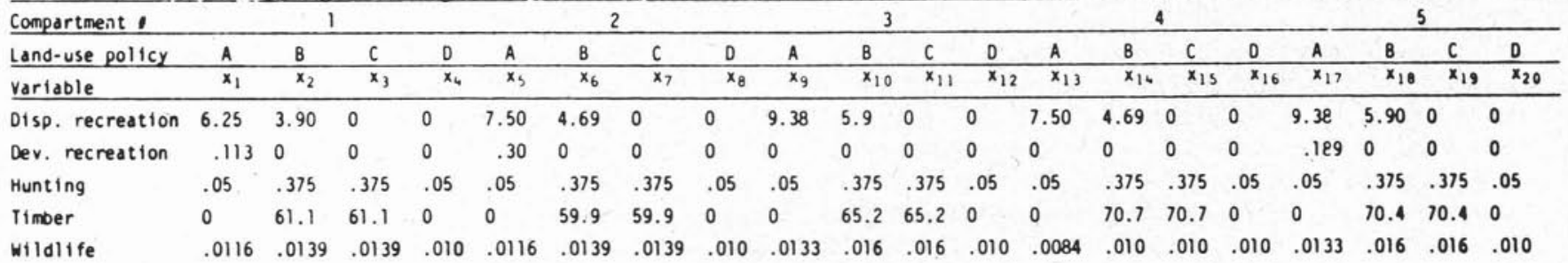

Table 5. Continued

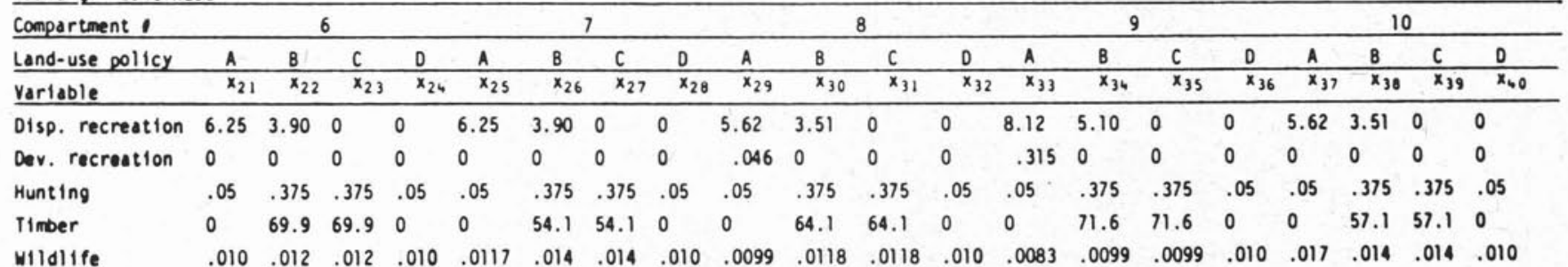

Table 5 Continued

\begin{tabular}{|c|c|c|c|c|c|c|c|c|c|c|c|}
\hline Land-use pollcy & $\mathrm{di}_{\mathrm{i}}$ & $d_{1}^{7}$ & $d_{2}^{-}$ & $d_{2}^{+}$ & $d_{3}^{-}$ & $d_{3}^{7}$ & $d_{4}$ & $d_{4}^{t}$ & $d_{5}^{-}$ & dit & Goals (Demands) \\
\hline Variable & $x_{41}$ & $x_{42}$ & $x_{43}$ & $x_{44}$ & $x_{45}$ & $x_{46}$ & $x_{47}$ & $x_{48}$ & $x_{49}$ & $x_{50}$ & \\
\hline Disp. recreation & 1 & -1 & 0 & 0 & 0 & 0 & 0 & 0 & 0 & 0 & $G_{1}=1000$ disp. v.d./year \\
\hline Dev. recreation & 0 & 0 & 1 & -1 & 0 & 0 & 0 & 0 & 0 & 0 & $G_{2}=320$ dev. v.d./year \\
\hline Hunting & 0 & 0 & 0 & 0 & 1 & -1 & 0 & 0 & 0 & 0 & $G_{3}=957$ hunter v.d./year \\
\hline Timber & 0 & 0 & 0 & 0 & 0 & 0 & 1 & -1 & 0 & 0 & $G_{4}=20,000 ; 120,000 ; 364,571 \mathrm{~m}^{3}$ \\
\hline Wildilfe & 0 & 0 & 0 & 0 & 0 & 0 & 0 & 0 & 1 & -1 & $G_{s}=125$ deer \\
\hline
\end{tabular}

Table 6. Deviations from each goal for the 2-, 12-, and 36- planning horizons and the four priority setting (cases) in Policy Group I. Number in brackets show the only differences observed for Policy Group II.

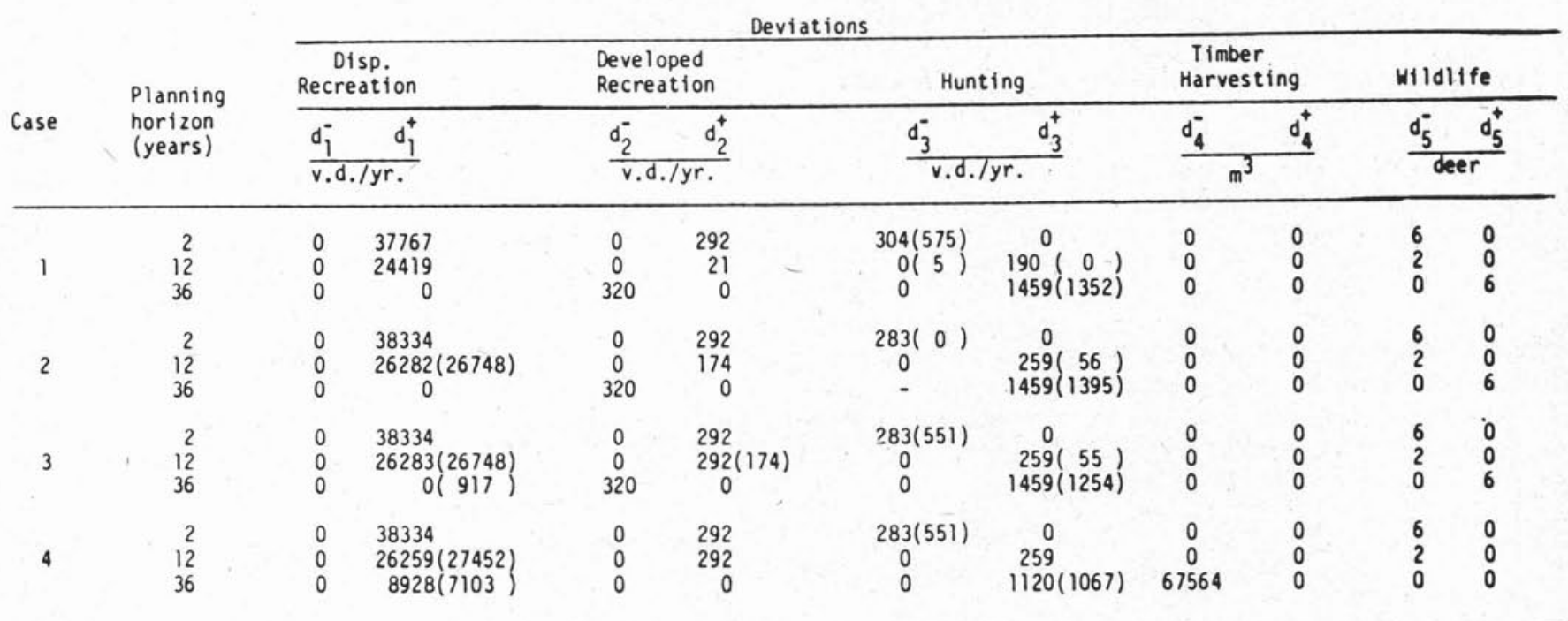

\section{Discussion}

Different priorities affect goal achievements (Table 6) as follows: giving top priority to developed recreation requires that certain areas of the land with high recreational potential be protected from timber harvesting. Especially the long-term developed recreational goal may thus interfere with the overall intent of cutting all merchantable timber within 36 years. Short-and medium-term developed recreation goals, however, are exceeded in each case regardless of priority. The shortand medium term dispersed recreational goals are also exceeded by a considerable margin, indicating that the dispers- ed recreational goal as set is very conservative in view of the recognized capacity of the land for general outdoor enjoyment.

Short-term plans, however, interfere with the low-priority hunting and wildlife goals, while medium- to long-term plans offer much in reducing the short fall in either case without change of priority. These benefits, however, can only occur as long as the timber is harvested according to the wildlife enhancing formula mentioned above.

Hunting restrictions (Policy Group II versus I) do not seem to introduce additional conflicts except that the short-term underachievement of the hunting goal is somewhat 
magnified. Also, the optimal land-use allocation pattern (Table 7 ) is hardly affected. Hence a simple consideration for safety, at least in this instance, seems to go a long way without generating further complexity to the problem.

The land-use allocation for each priority setting and planning horizon in Table 7 may serve as an optimal framework for drawing up cutting schedules. Notice that compartment preferences for cutting are not strong for the short- and medium-term planning horizons. Long-term planning horizons, however, dictate the optimal land-use vigorously. As expected, long-term preferences for land allocation are given to compartments with high recreational potential.

\section{Concluding Remarks}

Goal programming can play a significant role in multiple land-use planning of forested land by providing a mathematical model which:

(i) shows planners how land allocations for various uses will change over time under distinct and varying combinations of land-use policies, goals and priorities;

(ii) aids in distinguishing what activities are most limiting (in this case timber harvesting) and may require priority adjustment, or adjustment of the length of the planning horizon;

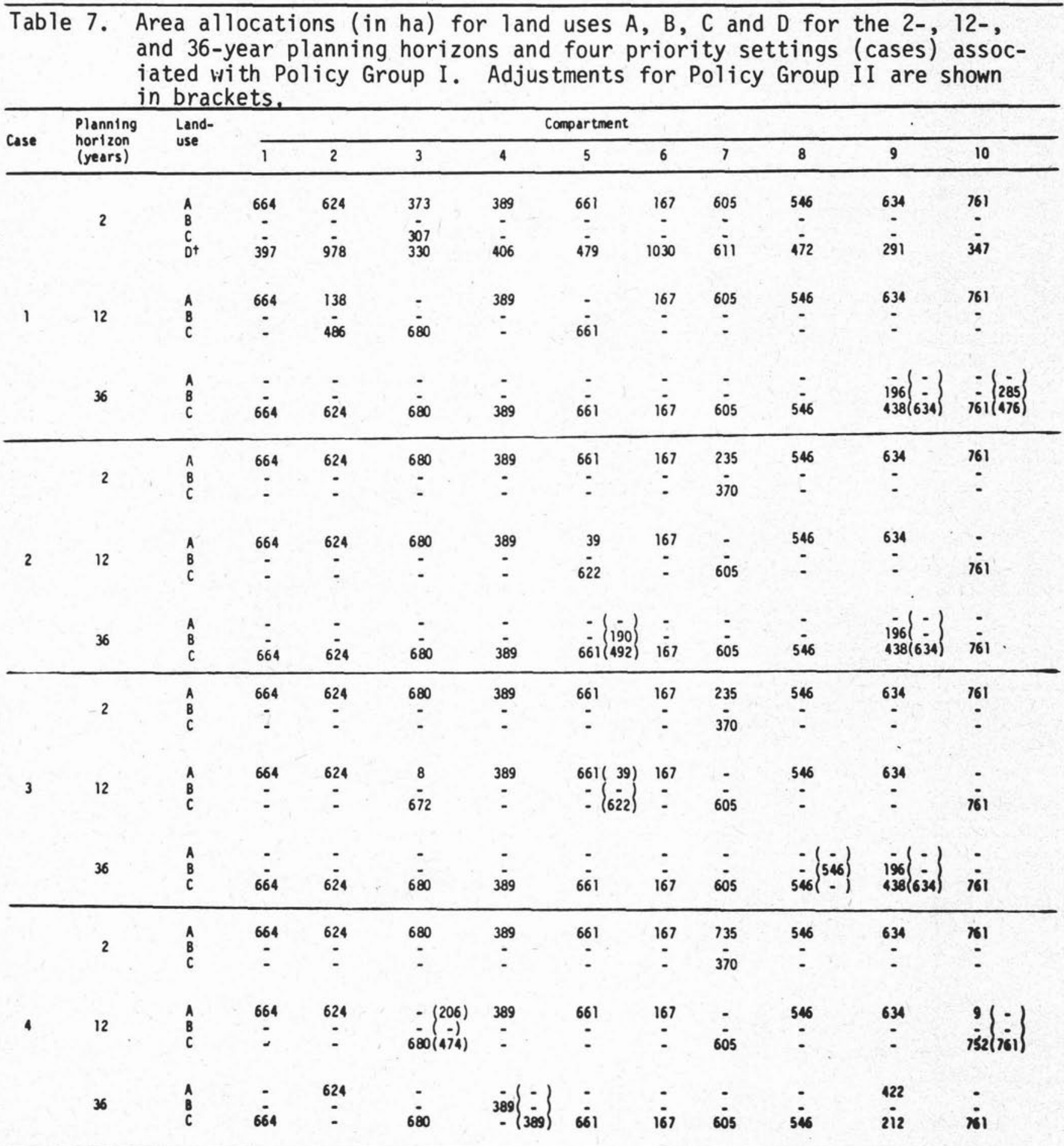

\footnotetext{
${ }^{+}$Allocation for Plan-use Policy $D$ is the same for all cases and planning horizons.
} 
(iii) helps to resolve land-use conflicts in a rational manner;

(iv) yields a framework for optimal land-use allocations;

(v) avoids the problem of sub-optimization, where each land-use is optimized without regard to the other uses, and perhaps worse, without regard to land capability coefficients and land-use constraints;

(vi) once the goal program has been established for a region, goal programming may be applied for each subregion.

Any multiple land-use plan, once quantitatively formulated by the goal programming procedure, should by no means be considered inflexible and fixed. Instead the plan should be updated from time to time by:

(i) systematically removing any uncertainty associated with the "first guess" assessment of the land capability coefficients,

(ii) by including new policies and/or priorities,

(iii) by drawing up a new plan for the next planning horizon (after the current planning horizon has expired) taking full account of (for example) past cutting records and a new merchantable timber distribution pattern, and

(iv) by making the necessary adjustments following major "catastrophies" of any sort, e.g. insect infestations, forest fires, extensive blowdowns, long-term flooding, or any other catastrophe making the current, existing land-use plan unworkable.

Familiarity with the goal programming procedure, once acquired, should make updating an easy task and, hopefully, would allow resource and land-use managers to cast quick and informed "educated glances" at any "plausible future", and plan accordingly.

\section{Acknowledgements}

We acknowledge the help of Professor A.T. Easley and Dr. D.M. Keppie who provided much needed advice. Special thanks are due to Mr. S. Behun and Mr. B. Sergeant for developing the interactive goal-programming computer routine, to CFB Gagetown and the Canadian Forestry Service for general assistance, to UNB's Faculty of Forestry Class of 1980 for providing the basic information and to the two reviewers of this paper for making helpful suggestions. This contribution is dedicated to Professor Norman L. Kissick, who - through his initiative, encouraging support and long-standing interest in land-use planning - made this study possible.
References

Bell, E.F. 1976. Goal programming for land use planning. USDA Forest Service. Gen. Tech. Rep. PNW-53. Pac Northwest Forest and Range Exp. Stn., Portland, Oreg., 12 .

Bottoms, E.F. 1976. General goal programming users manual. Washington Dept. of Agric. For. Service, Land Use Planning National Forest System 20250, Report No. 2, 69 p.

Burckhart, H.E., R. Dean Stuck, W.A. Leuschner, and M.R. Reynolds. 1978. Allocating inventory resources for multipleuse planning. Can. J. For. Res. 8: 100-110.

Burnett, G.W. and D.G. Conklin. 1979. Inventorying recreation potentials on dispersed tracts. J. of For. 79: 765-768.

CFB Gagetown Land Use Plan, 1980. Integrated land-use plan for the southwestern section of CFB Gagetown. University of New Brunswick. Faculty of Forestry. $184 \mathrm{p}$.

Dane, C.W., N.C. Meador and J.B. White. 1977. Goal programming in land-use planning. J. of For. 77: 325-329.

Duerr, W.A., D.E. Teeguarden, N.B. Christiansen, and S. Guttenburg. 1979. Forest resource management. Decisionmaking cases and principles. W.B. Saunders Co. Philadelphia. $612 \mathrm{p}$.

Dyer, A.A., J.G. Hof, J.W. Kelly, S.A. Crim, and G.S. Alward. 1979. Implications of goal programming in forest resource allocation. For. Sci. 25: 535-543.

Field, R.C., P.E. Dress, and J.C. Fortson. 1980. Complementary linear and goal programming procedures for timber harvest scheduling. Forest Sci. 26: 121-133.

Field, D.B. 1973. Goal programming for forest management. Forest Sci. 19: 125-135.

Hill, A. et al. 1971. Methodology for Ontario Recreation Land Inventory. Dept. of Lands and Forests. $49 \mathrm{p}$.

Hillier, F.S. and G.J. Lieberman. 1974. Operations research. Holden-Day Inc. San Francisco. 800 p.

Hrubes, R.J. and G. Rensi. 1981. Implications of goal programming in forest resource allocation: some comments. Forest Sci. 27: 454-459.

Lee, S.M. 1972. Goal programming for decision analysis. Auerbach Publ. Philadelphia. $387 p$

Manning, G.H. 1971. Linear programming, resource allocation and non-market benefits. Dept. of the Env., Can. For. Serv. Publ. No. $1298,18 p$

Nautiyal, J.C., H.S. Ngo and H.K. Thadaney. 1975. Land use for planning: a practical application of mixed integer programming. INFOR 13: 19-35.

Omi, P.N., J.L. Murphy and L.C. Wensel. 1981. A linear programming model for wildland fuel management planning. For. Sci. 27: 81-94

Rustagi, K.P. 1973. Forest management planning for timber production: a goal programming approach. Yale Sch. Forest and Environ. Studies Bull. 89, Yale Univ. New Haven Conn., 80 p.

Steuer, R.E. and A.T. Schuler. 1978. An interactive multipleobjective linear programming approach to a problem in forest management. Operations research 26: 254-269.

Ware, G.O. and J.L. Clutter. 1971. A mathematical programming system for the management of industrial forests. For. Sci. 17: 428-445.

\section{kbm FORESTRY CONSULTANTS INC.}

\author{
360 MOONEY STREET \\ THUNDER BAY, ONTARIO \\ P7B 5R4 \\ TEL.: $344-0811$
}

RESOURCE INVENTORY -

FOREST MANAGEMENT PLANNING

SILVICULTURAL SPECIALISTS

SYSTEM DESIGN AND CONTRACT

\section{EDWARD}

\section{S. \\ FELLOWS}

FORESTRY \& FOREST PRODUCTS CONSULTANT

P.O. Box 354, 404 Queen St., FREDERICTON, N. B.

Registered Professional

Forester (N. B.)

MEMBER:

Canadian Institute of Forestry

Forest Products Research Society, Etc.

INDUSTRY DEVELOPMENT - FOREST PRODUCTS ECONOMIC FOREST POLICY \& ADMINISTRATION 